\title{
Studies on the Protective Effects of Scutellarein against Neuronal Injury by Ischemia through the Analysis of Endogenous Amino Acids and $\mathrm{Ca}^{2+}$ Concentration Together with $\mathrm{Ca}^{2+}$-ATPase Activity
}

\author{
Hao Tang, Ze-Xi Dong, Ting Gu, Nian-Guang Li, Yu-Ping Tang, Qian-Ping Shi, \\ Jian-Ming Guo, Peng-Xuan Zhang, and Jin-Ao Duan \\ Jiangsu Collaborative Innovation Center of Chinese Medicine Resources Industrialization, \\ Jiangsu Key Laboratory for High Technology Research of TCM Formulae, and National and \\ Local Collaborative Engineering Center of Chinese Medicine Resources, Nanjing University of Chinese Medicine, \\ Nanjing 210023, China \\ Correspondence should be addressed to Nian-Guang Li; linianguang@163.com and Yu-Ping Tang; yupingtang@njucm.edu.cn
}

Received 21 January 2015; Revised 24 May 2015; Accepted 28 May 2015

Academic Editor: Patricia Valentao

Copyright (C) 2015 Hao Tang et al. This is an open access article distributed under the Creative Commons Attribution License, which permits unrestricted use, distribution, and reproduction in any medium, provided the original work is properly cited.

\begin{abstract}
Scutellarin, which is extracted from the dried plant of Erigeron breviscapus, has been reported to protect the neural injury against excitotoxicity induced by ischemia. However, there are a few studies on the protective effects of scutellarein, which is the main metabolite of scutellarin in vivo. Thus, this study investigated the neuroprotective effects of scutellarein on cerebral ischemia/reperfusion in rats by bilateral common carotid artery occlusion (BCCAO) model, through the analysis of endogenous amino acids using HILIC-MS/MS, and evaluation of $\mathrm{Ca}^{2+}$ concentration together with $\mathrm{Ca}^{2+}$-ATPase activity. The results showed that scutellarein having good protective effects on cerebral ischemia/reperfusion might by decreasing the excitatory amino acids, increasing the inhibitory amino acids, lowing intracellular $\mathrm{Ca}^{2+}$ level, and improving $\mathrm{Ca}^{2+}$-ATPase activity, which suggested that scutellarein might be a promising potent agent for the therapy of ischemic cerebrovascular disease.
\end{abstract}

\section{Introduction}

Ischemic cerebrovascular disease is the main cause of disability and death among the elderly people [1]. The increasing evidences showed that the excessive release of various amino acid neurotransmitters is one pathogenesis during ischemia reperfusion [2], indicating that the amino acid levels could be diagnostic markers. The depolarization is mediated by the metabolic failure which is caused by ischemia, and the results indicate that there is an influx of $\mathrm{Ca}^{2+}$ via voltagesensitive $\mathrm{Ca}^{2+}$ channels, thus initiate a flood of amino acid neurotransmitters, especially glutamate and aspartic acid [3], release into the synaptic cleft. The excitatory amino acids, which are the most important amino acid neurotransmitters, could induce a cascade of events leading to cell death [4, 5]. However, $\gamma$-aminobutyric acid (GABA), as an inhibitory amino acid, plays a neuroprotective role in vivo $[6,7]$. Thus, the determination of these amino acid neurotransmitters is very important to evaluate the global cerebral ischemic injury.

Erigeron breviscapus (Vant.) Hand.-Mazz., which mainly grows in Yunnan province of China, has been used for centuries as an important Chinese traditional herbal medicine to treat ischemic cerebrovascular diseases. Previous studies have demonstrated that breviscapine, which is extracted from the dried whole plant of Erigeron breviscapus, has neuroprotective effect against glutamate-induced excitotoxicity, by inhibiting the accumulation of intracellular $\mathrm{Ca}^{2+}$ and upregulating X-linked inhibitor of apoptosis protein (XIAP) expression in hippocampal neurons [8]. Tao et al. found that the breviscapus ethanol extract could inhibit GABA transaminase (GABA-T) and succinic semialdehyde dehydrogenase (SSADH) in the brain tissue to increase the GABA level 


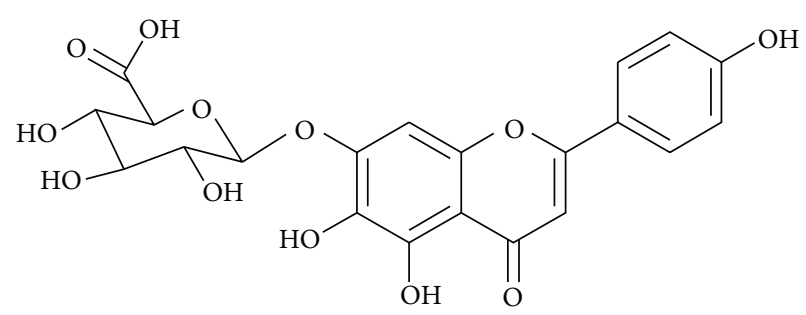

Scutellarin<smiles>O=c1cc(-c2ccc(O)cc2)oc2cc(O)c(O)c(O)c12</smiles>

Scutellarein

FIGURE 1: The chemical structures of scutellarin and scutellarein.

[9]. Scutellarin (Figure 1), the major bioactive constituent in breviscapine, possesses potent pharmacological effects similar to those of the herb. Many studies showed that scutellarin had a markedly neuroprotective activity against ischemiainduced injury by its anti-excitotoxicity, blocking $\mathrm{Ca}^{2+}$ channels, scavenging of reactive oxygen species, and so forth $[10,11]$. Interestingly, some researchers found that scutellarin was mainly absorbed in the form of its hydrolyzed product scutellarein (Figure 1) by intestines [12], and scutellarein was much easier to be absorbed with the triple bioavailability, after oral administration of these two compounds in equal amount [13]. A recent research indicated that scutellarein had better protective effect than scutellarin in rat cerebral ischemia [10]. However, there are a few studies on the protective effect of scutellarein against excitotoxicity, which is induced by excitatory neurotransmitters. Therefore, the aim of this study was to evaluate the possible protective effect of scutellarein against neuronal injury, through the analysis of endogenous amino acids, and $\mathrm{Ca}^{2+}$ concentration together with $\mathrm{Ca}^{2+}$ ATPase activity.

\section{Materials and Methods}

2.1. Materials. Scutellarein was prepared according to our previous procedure [14-16]. Chemicals standards of phenylalanine (Phe), $\gamma$-aminobutyric acid (GABA), leucine (Leu), valine (Val), methionine (Met), taurine (Tau), alanine (Ala), hydroxyproline (H-pro), glycine (Gly), glutamic acid (Glu), glutamine (Gln), serine (Ser), asparagines (Asn), citrulline (Cit), aspartic acid (Asp), arginine (Arg), and lysine (Lys) were purchased from Sigma-Aldrich (St. Louis, MO). The acetonitrile and formic acid were all of HPLC grade and purchased from Merck (Darmstadt, Germany). Ammonium formate (analytical grade) was purchased from the Shanghai Chemical Reagent Factory (Shanghai, China). Pure water for UHPLC analysis was purified using a Milli-Q water purification system (Millipore, Billerica, MA) and used for all solutions and dilutions. Other reagents and chemicals were of analytical grade.

All male Wister rats $(240 \pm 20$ g, clean grade, Certification SCXK 2009-0001) were obtained from Shanghai SLAC Laboratory Animal Co. Ltd. (Shanghai, China). All rats were bred on $12 \mathrm{~h}$ dark-light cycle, with temperature of $23 \pm 2^{\circ} \mathrm{C}$ and humidity of $60 \pm 5 \%$, and they have free access to the food and water. The rats were cared in accordance with the Guide for the Care and Use of Laboratory Animals (US National Research Council, 1996) and the related ethics regulations of our university.

2.2. Drug Administration and Surgery. The rats were randomly divided into six groups ( $n=6$ /group) including shamoperation group, bilateral common carotid artery occlusion (BCCAO) rats without pretreatment (model group), and BCCAO rats pretreated with scutellarein $(0.09,0.17$, $0.35 \mathrm{mmol} / \mathrm{kg}$ ). The rats in the treatment groups were intragastrically administrated with scutellarein under body weight for 6 consecutive days, while the rats in the sham-operated and model group were intragastrically administrated with equal volume of $0.25 \%$ CMC-Na; $10 \%$ of choral hydrate ( $350 \mathrm{mg} / \mathrm{kg}$ ip) was used for anesthesia on the seventh day. The bilateral common carotid arteries were exposed and ligated with 0 thread for $30 \mathrm{~min}$ to induce cerebral ischemia; following cerebral ischemia, reperfusion was achieved by declamping the arteries for $15 \mathrm{~min}$. Then repeated ischemia was allowed for $30 \mathrm{~min}$ and reperfusion was allowed for $22 \mathrm{~h}$. While the rats which only had the bilateral isolation of bilateral common carotid arteries (without occlusion) served as the sham-operated group. Anesthetized rats were placed on a heating pad during recovery from anesthesia to maintain the body temperature at $37.0 \pm 0.5^{\circ} \mathrm{C}$ after surgery $[17,18]$.

2.3. Preparation of Standard Solutions. A mixed standard solution containing 17 analytes was dissolved in water, and the concentrations of these analytes were shown as follows: GABA, $23.2 \mu \mathrm{g} / \mathrm{mL}$; Gly, $51.6 \mu \mathrm{g} / \mathrm{mL}$; Glu, $158 \mu \mathrm{g} / \mathrm{mL}$; Tau, $20.4 \mu \mathrm{g} / \mathrm{mL}$; Asp, $16.8 \mu \mathrm{g} / \mathrm{mL}$; Leu, $172.0 \mu \mathrm{g} / \mathrm{mL}$; Met, $20.0 \mu \mathrm{g} /$ $\mathrm{mL}$; Phe, $21.6 \mu \mathrm{g} / \mathrm{mL}$; Ala, $122.0 \mu \mathrm{g} / \mathrm{mL}$; Cit, $24.0 \mu \mathrm{g} / \mathrm{mL}$; Gln, $19.2 \mu \mathrm{g} / \mathrm{mL}$; Asn, $31.6 \mu \mathrm{g} / \mathrm{mL}$; Ser, $233.6 \mu \mathrm{g} / \mathrm{mL}$; Val, $21.6 \mu \mathrm{g} /$ $\mathrm{mL}$; H-pro, $32.8 \mu \mathrm{g} / \mathrm{mL}$; Lys, $22.4 \mu \mathrm{g} / \mathrm{mL}$; Arg, $22.8 \mu \mathrm{g} / \mathrm{mL}$. These mixed standard solutions were then diluted to appropriate concentration for building calibration curves. The standard solutions were filtered through a $0.22 \mu \mathrm{m}$ membrane prior to injection.

2.4. Preparation of Sample Solutions. All rats were anesthetized with $10 \%$ choral hydrate and then sacrificed by decapitation. The complete cerebrum was removed from the skull, and the hippocampus tissue was carefully isolated; subsequently, the tissues were stored at $-80^{\circ} \mathrm{C}$. $0.1 \mathrm{~g}$ ischemia 
tissue was homogenized in appropriate cold normal saline. The obtained supernatants were centrifuged at $3000 \mathrm{rpm}$ for $10 \mathrm{~min}$ at $4^{\circ} \mathrm{C}$. After vortex for $2 \mathrm{~min}$ and centrifugation at $13000 \mathrm{rpm}$ for $10 \mathrm{~min}$, the upper layer was transferred into another tube, and was then added 3 times of methanol. The concentrate was evaporated to dryness in a rotary evaporator at $25^{\circ} \mathrm{C}$ and then redissolved in $200 \mu \mathrm{L}$ of $50 \%$ acetonitrile in water using vortex-mixing for $3 \mathrm{~min}$; after being centrifuged at $13000 \mathrm{rpm}$ for $15 \mathrm{~min}$ at $4^{\circ} \mathrm{C}$, the upper layer was filtered through a $0.22 \mu \mathrm{m}$ membrane prior to injection.

2.5. HILIC-UPLC-TQ-MS/MS Analysis Conditions. Chromatographic experiments were determined by a Waters ACQUITY UPLC system (Waters, Milford, MA) equipped with a binary solvent delivery system and autosampler. ACQUITY UPLC BEH column $(2.1 \mathrm{~mm} \times 100 \mathrm{~mm}, 1.7 \mu \mathrm{m}$, Waters) was applied for all analysis. A gradient of $10 \mathrm{mM}$ ammonium formate and $0.15 \%$ formic acid in water (solvent A) and $2 \mathrm{mM}$ ammonium and $0.15 \%$ formic acid in acetonitrile was used. A linear gradient elution was as follows: initial-6 min, $15-20 \% \mathrm{~A}$; 6-10 min, 20-30\% A; 10-12 min, 30$40 \% \mathrm{~A}$; then the column was equilibrated for $6 \mathrm{~min}$ in the initial conditions. The flow rate of the mobile phase was set to $0.4 \mathrm{~mL} / \mathrm{min}$, an aliquot of $5 \mu \mathrm{L}$ sample solution was injected into the BEH column, and the column temperature was maintained at $35^{\circ} \mathrm{C}$. Mass spectrometry was carried out on a Waters Xevo TQ tandem quadrupole mass spectrometer (Micromass MS Technologies, Manchester, UK) using an ESI source operated in positive ion mode. The parameters in the source were set as follows: capillary voltage, $3.0 \mathrm{kV}$; source temperature, $150^{\circ} \mathrm{C}$; desolvation temperature, $550^{\circ} \mathrm{C}$; cone gas flow, $50 \mathrm{~L} / \mathrm{h}$; desolvation gas flow, $1000 \mathrm{~L} / \mathrm{h}$. The analyte detection was performed by using multiple reactions monitoring (MRM). The cone voltage and collision energy were optimized for each analyte. The dwell time was automatically set by the software.

2.6. Measurements of $\mathrm{Ca}^{2+}$ Concentration and $\mathrm{Ca}^{2+}$-ATPase Activity. All rats were anesthetized with $10 \%$ choral hydrate and sacrificed by decapitation. The brain was separated and placed on ice; the brain cortex tissue was carefully isolated and homogenized with ice-cold normal saline to be $10 \%(\mathrm{w} / \mathrm{v})$ homogenates and then stored at $-80^{\circ} \mathrm{C}$ until assays were performed. The $\mathrm{Ca}^{2+}$ concentration and $\mathrm{Ca}^{2+}$-ATPase activities were, respectively, determined using appropriative detection kits. Analysis of variance was used to determine the difference in $\mathrm{Ca}^{2+}$ concentration and the $\mathrm{Ca}^{2+}$-ATPase activity. Repeated measurement or multivariate analysis of variance was used to compare the amino acids concentrations. All results were expressed as mean \pm S.D, and a value of $P<0.05$ was considered statistically significant.

\section{Results}

3.1. Effect of Scutellarein on the Contents of Amino Acids. It was difficult to simultaneously analyze the endogenous amino acids in biological samples, because of their structure diversity, high polarity, and the absence of specific chromophores. In the past decade, many analytical methods have been used and they can be classified into two categories, the first approach for analysis of amino acids was the derivation method applying the reversed-phase highperformance liquid chromatography (RP-HPLC) or capillary electrophoresis (CE) and gas chromatography (GC) coupled with optical or MS detection. This derivation method used orthophthaldehyde (OPA), phenyl isothiocyanate (PITC), 9fluorenylmethyl chloroformate (FMOC), and 1-fluoro-2,4dinitrobenzene (DNFB) as derivation agents. Unfortunately, most of these derivation methods have some disadvantages including instable derivative, low yield, interferences caused by the reagent, or time-consuming derivatization procedures [19-22]. Another approach is ion-exchange HPLC coupled with electrochemical detection and CE-MS methods without derivatization. Most of these methods suffered from some drawbacks including lack of analyte specificity, low throughput, and comparatively poor reproducibility [19]. Our group [23] developed a sensitive and rapid method for the simultaneous determination of amino acids in fruits of Ziziphus jujuba without derivatization using hydrophilic interaction liquid chromatography coupled with tandem mass spectrometry (HILIC-MS/MS). The quantification of endogenous amino acids in brain tissues without derivatization had some advantages because it avoids instable derivatives and reagent interferences. So the 17 endogenous amino acids including Phe, GABA, Leu, Val, Met, Tau, Ala, H-pro, Gly, Glu, Gln, Ser, Asn, Cit, Asp, Arg, and Lys were analyzed by HILIC-MS/MS in this research.

The content changes of the neurotransmitter amino acids in hippocampus were shown in Table 1. It was found that Glu, Tau, Asp, Leu, Met, Phe, Cit, Gln, H-pro, Lys, and Arg in the model group changed significantly in comparison to the sham-operated group, such as the Glu content in the Sham group being $42.66 \mu \mathrm{g} / \mathrm{g}$; however, the Glu content in the model group was $85.52 \mu \mathrm{g} / \mathrm{g}$. From Table 1, it was clearly showed that $0.09 \mathrm{mmol} / \mathrm{kg}$ scutellarein could decrease significantly the contents of excitatory amino acids including Gly, Glu, Asp, Leu, Met, Phe, Ala, Cit, Gln, Asn, Val, H-pro, Lys, and Arg by 3.863, 69.72, 4.737, 19.93, 4.897, 16.85, 23.10, 2.391, $134.5,4.391,9.013,3.122,3.832$, and $8.831 \mu \mathrm{g} / \mathrm{g}$, respectively, compared with the model group. By contrast, $0.09 \mathrm{mmol} / \mathrm{kg}$ scutellarein significantly increased the content of inhibitory amino acid such as GABA by $121.8 \mu \mathrm{g} / \mathrm{g}$. After treatment with scutellarein, the contents of Glu, Asp, Leu, Met, Phe, Cit, Gln, Asn, Val, H-pro, Lys, and Arg decreased greatly $(68.95,3.641$, $17.73,3.845,15.71,2.122,126.4,3.472,8.912,2.821,3.553$, and $8.262 \mu \mathrm{g} / \mathrm{g}$, resp.) at the dose of $0.17 \mathrm{mmol} / \mathrm{kg}$ and fell slightly at the dose of $0.35 \mathrm{mmol} / \mathrm{kg}$. In contrast, the GABA and Tau contents significantly increased and reached the highest level $(135.9 \mu \mathrm{g} / \mathrm{g}$ and $112.1 \mu \mathrm{g} / \mathrm{g})$ at the dose of $0.35 \mathrm{mmol} / \mathrm{kg}$.

\subsection{Determination of $\mathrm{Ca}^{2+}$ Concentration and $\mathrm{Ca}^{2+}$-ATPase} Activity. The $\mathrm{Ca}^{2+}$ concentration and $\mathrm{Ca}^{2+}$-ATPase activities were, respectively, determined using appropriative detection kits. Results presented in Table 2 showed the $\mathrm{Ca}^{2+}$ 
TABLE 1: Effects of scutellarein on contents of 17 amino acid neurotransmitters in brain of cerebral ischemic/reperfusion rats $(\mu \mathrm{g} / \mathrm{g}, \bar{x} \pm s$, $n=6)$.

\begin{tabular}{|c|c|c|c|c|c|}
\hline Analyte & $\begin{array}{l}\text { Sham } \\
(\mu \mathrm{g} / \mathrm{g})\end{array}$ & $\begin{array}{l}\text { Model } \\
(\mu \mathrm{g} / \mathrm{g})\end{array}$ & $\begin{array}{c}\text { Scutellarein } \\
(0.09 \mathrm{mmol} / \mathrm{kg})\end{array}$ & $\begin{array}{c}\text { Scutellarein } \\
(0.17 \mathrm{mmol} / \mathrm{kg})\end{array}$ & $\begin{array}{c}\text { Scutellarein } \\
(0.35 \mathrm{mmol} / \mathrm{kg})\end{array}$ \\
\hline GABA & $111.6 \pm 0.2579$ & $119.9 \pm 0.8276^{\triangle \Delta}$ & $121.8 \pm 1.263^{*}$ & $124.1 \pm 1.191^{* *}$ & $135.9 \pm 6.187^{*}$ \\
\hline Gly & $3.332 \pm 0.1681$ & $4.607 \pm 0.2127^{\triangle}$ & $3.863 \pm 0.1112^{*}$ & $3.961 \pm 0.2612^{*}$ & $3.558 \pm 0.1295^{* *}$ \\
\hline Glu & $42.66 \pm 4.420$ & $85.52 \pm 5.436^{\triangle}$ & $69.72 \pm 3.356^{*}$ & $68.95 \pm 11.10$ & $61.80 \pm 4.438^{* *}$ \\
\hline Tau & $55.86 \pm 3.225$ & $96.11 \pm 2.247^{\triangle \Delta}$ & $81.11 \pm 2.153$ & $91.54 \pm 3.421^{*}$ & $112.1 \pm 5.386^{*}$ \\
\hline Asp & $2.413 \pm 0.3432$ & $5.214 \pm 0.2840^{\triangle \Delta}$ & $4.737 \pm 0.2623$ & $3.641 \pm 0.2933^{*}$ & $3.133 \pm 0.2145^{* *}$ \\
\hline Leu & $11.35 \pm 1.211$ & $21.84 \pm 1.342^{\triangle \Delta}$ & $19.93 \pm 0.8321^{* *}$ & $17.73 \pm 1.231^{* *}$ & $15.50 \pm 2.320^{* *}$ \\
\hline Met & $3.432 \pm 0.1210$ & $5.041 \pm 0.2140^{\triangle \triangle}$ & $4.897 \pm 0.3254^{* *}$ & $3.845 \pm 0.0231^{*}$ & $3.792 \pm 0.1100^{*}$ \\
\hline Phe & $10.08 \pm 2.113$ & $18.92 \pm 2.513$ & $16.85 \pm 2.653^{*}$ & $15.71 \pm 1.216^{* *}$ & $12.53 \pm 0.3245^{* *}$ \\
\hline Ala & $18.78 \pm 2.165$ & $25.52 \pm 3.245^{\triangle}$ & $23.10 \pm 0.4265^{*}$ & $24.17 \pm 3.254^{* *}$ & $20.00 \pm 0.6530$ \\
\hline Cit & $1.813 \pm 0.2311$ & $2.562 \pm 0.4301^{\triangle}$ & $2.391 \pm 0.1254^{* *}$ & $2.122 \pm 0.4322^{*}$ & $2.023 \pm 0.3251^{* *}$ \\
\hline Gln & $107.1 \pm 3.248$ & $140.7 \pm 1.342^{\triangle}$ & $134.5 \pm 6.231^{* *}$ & $126.4 \pm 4.563^{*}$ & $117.0 \pm 3.258^{*}$ \\
\hline Asn & $3.072 \pm 0.1281$ & $4.713 \pm 0.4381^{\triangle}$ & $4.391 \pm 0.4351$ & $3.472 \pm 0.1043^{* *}$ & $3.533 \pm 0.2549^{* *}$ \\
\hline Ser & $27.13 \pm 1.151$ & $29.44 \pm 1.432$ & $28.57 \pm 4.324$ & $28.95 \pm 3.980^{*}$ & $28.38 \pm 1.543^{* *}$ \\
\hline Val & $8.201 \pm 0.3505$ & $9.192 \pm 0.5319^{\triangle}$ & $9.013 \pm 0.5600^{* *}$ & $8.912 \pm 0.5341^{* *}$ & $8.732 \pm 0.4533^{* *}$ \\
\hline H-pro & $2.301 \pm 0.2321$ & $3.303 \pm 0.5432^{\triangle}$ & $3.122 \pm 0.1120^{* *}$ & $2.821 \pm 0.2004^{* *}$ & $2.573 \pm 0.1043^{*}$ \\
\hline Lys & $1.562 \pm 0.2210$ & $4.071 \pm 0.2311^{\triangle \Delta}$ & $3.832 \pm 0.1240^{*}$ & $3.553 \pm 0.1043$ & $2.231 \pm 0.2034^{* *}$ \\
\hline Arg & $4.582 \pm 0.1211$ & $10.65 \pm 0.3218^{\triangle}$ & $8.831 \pm 0.5421^{* *}$ & $8.262 \pm 0.5902^{* *}$ & $6.801 \pm 0.6420^{* *}$ \\
\hline
\end{tabular}

Model groups compared with their sham groups, respectively $\left({ }^{\triangle} P<0.05,{ }^{\triangle} P<0.01\right)$, compared with model groups $\left({ }^{* *} P<0.01,{ }^{*} P<0.05\right)$.

TABLE 2: The content of $\mathrm{Ca}^{2+}$ and the activity of $\mathrm{Ca}^{2+}-\mathrm{ATPa} e$ in ischemia tissue.

\begin{tabular}{lcc}
\hline & $\begin{array}{c}\mathrm{Ca}^{2+} \\
(\mathrm{mmol} / \mathrm{L})\end{array}$ & $\begin{array}{c}\mathrm{Ca}^{2+} \text {-ATPase } \\
(\mathrm{molpi} / \mathrm{mgprot} / \mathrm{hour})\end{array}$ \\
\hline $\begin{array}{l}\text { Model group } \\
\text { Sham group }\end{array}$ & $34.13 \pm 6.873^{\triangle \Delta}$ & $4.215 \pm 0.4531^{\triangle \Delta}$ \\
$\begin{array}{l}\text { Scutellarein } \\
(0.09 \mathrm{mmol} / \mathrm{kg})\end{array}$ & $29.30 \pm 1.439^{*}$ & $6.544 \pm 0.3465$ \\
$\begin{array}{l}\text { Scutellarein } \\
(0.17 \mathrm{mmol} / \mathrm{kg})\end{array}$ & $25.83 \pm 3.438^{*}$ & $5.111 \pm 0.1554^{*}$ \\
$\begin{array}{l}\text { Scutellarein } \\
(0.35 \mathrm{mmol} / \mathrm{kg})\end{array}$ & $19.21 \pm 2.059^{* *}$ & $5.917 \pm 1.171^{*}$ \\
\hline
\end{tabular}

Model groups compared with their sham groups, respectively $\left({ }^{\triangle} P<0.01\right)$, compared with model groups $\left({ }^{* *} P<0.01,{ }^{*} P<0.05\right)$.

concentration and the $\mathrm{Ca}^{2+}$-ATPase activities in the shamoperated group, model group, and ischemic rats treated with various doses of scutellarein. The model group significantly increased the $\mathrm{Ca}^{2+}$ concentration in comparison to the shamoperated rats, indicating that ischemic-reperfusion significantly induced $\mathrm{Ca}^{2+}$ overload in the BCCAO model rats. After administration of scutellarein, the $\mathrm{Ca}^{2+}$ concentration decreased greatly in a dose-dependent manner compared to the model group. $\mathrm{Ca}^{2+}$-ATPase played a critical role in regulation of the intracellular calcium level. In the present study, we found that the activity of $\mathrm{Ca}^{2+}$-ATPase in the model group decreased significantly compared to the shamoperated group. However, the $\mathrm{Ca}^{2+}$-ATPase activity in the scutellarein pretreated group increased in a dose-dependent manner. These results indicated that the protective effect of scutellarein might be due to its cerebral neuroprotection by inhibiting $\mathrm{Ca}^{2+}$ overload and enhancing $\mathrm{Ca}^{2+}$-ATPase activity.

\section{Discussion}

The interstitial contents of neurotransmitter amino acids, especially excitatory amino acids and inhibitory amino acids, are often recognized as an index of neuronal injury. Excitatory amino acids were the important stimulant medium after receptor activation, which can be classified into two categories: the ionotropic receptor and metabotropic receptor, the former includes $\mathrm{N}$-methyl-D-aspartate (NMDA), $\alpha$-amino-3-hydroxy-methyl-4-isoxazole propionic acid (AMPA), and kainate (KA), and the latter includes L-(+)2-amino-4-phosphonobutyric acid (L-AP4), 1-amino-1,3dicarboxycyclopentane (ACPD), and L-quisqualic acid (L-QA). During cerebral ischemia, the excitatory amino acids were released pathologically from dying cells [24] and glutamate was recognized as a predominant neurotransmitter involved in the excitotoxicity process [25]. Firstly, the glutamate which was at the postsynaptic membrane bond to AMAP receptor and then led to $\mathrm{Na}^{+}$influx thus resulted in cerebral edema [26]. Simultaneously, Glu activated NMDA receptor leading to the entry of external $\mathrm{Ca}^{2+}$ and inositol triphosphate $\left(\mathrm{IP}_{3}\right)$ stimuli further induced the release of internal $\mathrm{Ca}^{2+}$ that was stored within mitochondria and endoplasmic reticulum $[27,28]$. It was widely believed that $\mathrm{Ca}^{2+}$, as a second messenger, played a key role in the development of ischemic cell damage $[29,30] . \mathrm{Ca}^{2+}$-ATPase, which was an important modulator of the intracellular calcium level, could pump $\mathrm{Ca}^{2+}$ back into the endoplasmic 


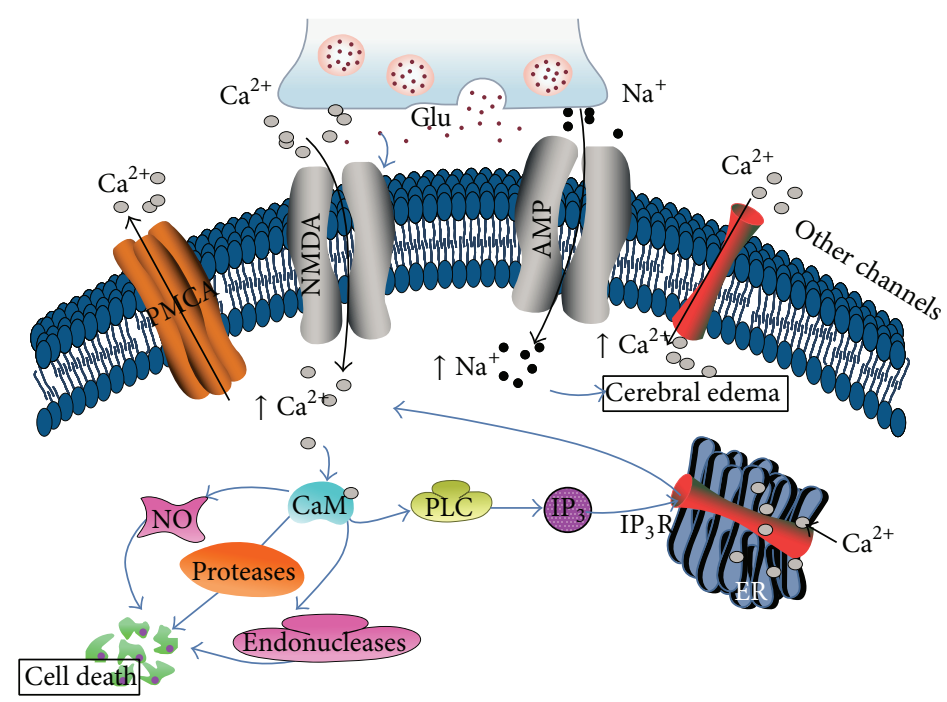

FIgURE 2: The possible mechanism of excitotoxicity during ischemia/reperfusion.

reticulum against a steep concentration gradient [31]. However, endoplasmic reticulum (ER) calcium homeostasis was disturbed during ischemia, because ATP was needed to fuel the ER $\mathrm{Ca}^{2+}$-ATPase [32]. Intracellular $\mathrm{Ca}^{2+}$-overload could activate calcium-dependent protein kinases, such as calpain, which ultimately destroyed cellular integrity (Figure 2) [33, 34]. In this process, we knew that the inhibition of the release of excitatory amino acids neurotransmitters might be expected to reduce cerebral ischemic injury.

In this study, we clearly found that scutellarein could significantly decreased the contents of excitatory amino acids including Gly, Glu, Asp, Leu, Met, Phe, Ala, Cit, Gln, Asn, Val, H-pro, Lys, and Arg. Furthermore, the contents of the inhibitory amino acids such as GABA and Tau increased significantly after treatment with scutellarein; these results suggested that scutellarein might attenuate the impairment of neuronal by BCCAO [35-37] via decreasing the excitatory amino acids (such as Gly, Glu, and Asp) contents and enhancing the inhibitory amino acids (GABA and Tau) contents. The measurement of the intracellular $\mathrm{Ca}^{2+}$ levels and the activity of $\mathrm{Ca}^{2+}$-ATPase in the brain tissues showed that there was sharp rise of $\mathrm{Ca}^{2+}$ and great decline of $\mathrm{Ca}^{2+}$-ATPase activity after ischemia/reperfusion; this phenomenon indicated that scutellarein might slow down the influx of $\mathrm{Ca}^{2+}$ and reduce the intracellular $\mathrm{Ca}^{2+}$ concentration during ischemia.

\section{Conclusion}

In summary, a reliable, simple, and sensitive method was developed for the identification and quantification of 17 endogenous amino acids in the brain tissue by using UPLCMS/MS. The $\mathrm{Ca}^{2+}$ concentration and the $\mathrm{Ca}^{2+}$-ATPase activity were also evaluated. These results showed that scutellarein might ameliorate the brain injury in the rats of cerebral ischemia reperfusion through decreasing the excitatory amino acids, increasing the inhibitory amino acids, lowing intracellular $\mathrm{Ca}^{2+}$ level, and improving $\mathrm{Ca}^{2+}$-ATPase activity. All these results indicated that scutellarein might have good protective effect on cerebral ischemia/reperfusion.

\section{Conflict of Interests}

The authors declare that there is no conflict of interests regarding the publication of this paper.

\section{Authors' Contribution}

Hao Tang, Ze-Xi Dong, Ting Gu, Qian-Ping Shi, and PengXuan Zhang performed the experiments. Nian-Guang Li and Jian-Ming Guo designed the experiments. Hao Tang and Nian-Guang Li wrote the paper. Yu-Ping Tang and Jin-Ao Duan revised the paper.

\section{Acknowledgments}

This work was supported by the National Natural Science Foundation of China $(81274058,21302225)$, the Program for New Century Excellent Talents by the Ministry of Education (NCET-12-0741), 333 High-Level Talents Training Project Funded by Jiangsu Province, Six Talents Project Funded by Jiangsu Province (2013-YY-010), Technology Innovation Venture Fund by Nanjing University of Chinese Medicine (CX201301), Project Funded by the Priority Academic Program Development of Jiangsu Higher Education Institutions, and Jiangsu Collaborative Innovation Center of Chinese Medicinal Resources Industrialization (ZDXMHT-1-13).

\section{References}

[1] G. A. Donnan, M. Fisher, M. Macleod, and S. M. Davis, "Stroke," The Lancet, vol. 371, no. 9624, pp. 1612-1623, 2008. 
[2] M. Oda, S. Kure, T. Sugawara et al., "Direct correlation between ischemic injury and extracellular glycine concentration in mice with genetically altered activities of the glycine cleavage multienzyme system," Stroke, vol. 38, no. 7, pp. 2157-2164, 2007.

[3] D. W. Choi and S. M. Rothman, "The role of glutamate neurotoxicity in hypoxic-ischemic neuronal death," Annual Review of Neuroscience, vol. 13, pp. 171-182, 1990.

[4] S. P. Butcher, R. Bullock, D. I. Graham, and J. McCulloch, "Correlation between amino acid release and neuropathologic outcome in rat brain following middle cerebral artery occlusion," Stroke, vol. 21, no. 12, pp. 1727-1733, 1990.

[5] D. L. Small and A. M. Buchan, "Mechanisms of cerebral ischemia: intracellular cascades and therapeutic interventions," Journal of Cardiothoracic and Vascular Anesthesia, vol. 10, no. 1, pp. 139-146, 1996.

[6] K. P. Madden, "Effect of $\gamma$-aminobutyric acid modulation on neuronal ischemia in rabbits," Stroke, vol. 25, no. 11, pp. 22712275, 1994.

[7] M. Tanabe, A. Nitta, and H. Ono, "Neuroprotection via strychnine-sensitive glycine receptors during post-ischemic recovery of excitatory synaptic transmission in the hippocampus," Journal of Pharmacological Sciences, vol. 113, no. 4, pp. 378386, 2010.

[8] X.-H. Xu, Y. Chen, and X.-X. Zheng, "Protective effects of breviscapine against cultured rat hippocampal neuronal toxicity induced by glutamate," Yaoxue Xuebao, vol. 42, no. 6, pp. 583588, 2007.

[9] Y. H. Tao, D. Y. Jiang, H. B. Xu, and X. L. Yang, "Inhibitory effect of Erigeron breviscapus extract and its flavonoid components on GABA shunt enzymes," Phytomedicine, vol. 15, no. 1-2, pp. 92-97, 2008.

[10] H. Tang, Y. P. Tang, N. G. Li et al., "Neuroprotective effects of scutellarin and scutellarein on repeatedly cerebral ischemiareperfusion in rats," Pharmacology Biochemistry and Behavior, vol. 118, pp. 51-59, 2014.

[11] L.-H. Qian, N.-G. Li, Y.-P. Tang et al., "Synthesis and bio-activity evaluation of scutellarein as a potent agent for the therapy of ischemic cerebrovascular disease," International Journal of Molecular Sciences, vol. 12, no. 11, pp. 8208-8216, 2011.

[12] J.-L. Zhang, Q.-M. Che, S.-Z. Li, and T.-H. Zhou, "Study on metabolism of scutellarin in rats by HPLC-MS and HPLCNMR," Journal of Asian Natural Products Research, vol. 5, no. 4, pp. 249-256, 2003.

[13] Q. M. Che, Y. Chen, L. Y. Pan et al., "Scutellarein's pharmacokinetics in rats," Chinese Journal of New Drugs, vol. 15, no. 18, pp. 1557-1561, 2006.

[14] J. O. Strom, A. Theodorsson, and E. Theodorsson, "Mechanisms of Estrogens' dose-dependent neuroprotective and neurodamaging effects in experimental models of cerebral ischemia," International Journal of Molecular Sciences, vol. 12, no. 3, pp. 1533-1562, 2011.

[15] R. Brouns and P. P. De Deyn, "The complexity of neurobiological processes in acute ischemic stroke," Clinical Neurology and Neurosurgery, vol. 111, no. 6, pp. 483-495, 2009.

[16] M. Hollmann, M. Hartley, and S. Heinemann, "Ca ${ }^{2+}$ permeability of KA-AMPA - gated glutamate receptor channels depends on subunit composition," Science, vol. 252, no. 5007, pp. 851-853, 1991.

[17] H. Shin, I. K. Hwang, K.-Y. Yoo et al., "Expression and changes of $\mathrm{Ca}^{2+}$-ATPase in neurons and astrocytes in the gerbil hippocampus after transient forebrain ischemia," Brain Research, vol. 1049, no. 1, pp. 43-51, 2005.
[18] Y. Gouriou, N. Demaurex, P. Bijlenga, and U. de Marchi, "Mitochondrial calcium handling during ischemia-induced cell death in neurons," Biochimie, vol. 93, no. 12, pp. 2060-2067, 2011.

[19] H. Kaspar, K. Dettmer, W. Gronwald, and P. J. Oefner, "Advances in amino acid analysis," Analytical and Bioanalytical Chemistry, vol. 393, no. 2, pp. 445-452, 2009.

[20] J. Qu, Y. Wang, G. Luo, Z. Wu, and C. Yang, "Validated quantitation of underivatized amino acids in human blood samples by volatile ion-pair reversed-phase liquid chromatography coupled to isotope dilution tandem mass spectrometry," Analytical Chemistry, vol. 74, no. 9, pp. 2034-2040, 2002.

[21] T. Langrock, P. Czihal, and R. Hoffmann, "Amino acid analysis by hydrophilic interaction chromatography coupled on-line to electrospray ionization mass spectrometry," Amino Acids, vol. 30, no. 3, pp. 291-297, 2006.

[22] N. Shama, S. W. Bai, B. C. Chung, and B. H. Jung, "Quantitative analysis of 17 amino acids in the connective tissue of patients with pelvic organ prolapse using capillary electrophoresistandem mass spectrometry," Journal of Chromatography B: Analytical Technologies in the Biomedical and Life Sciences, vol. 865, no. 1-2, pp. 18-24, 2008.

[23] S. Guo, J.-A. Duan, D. W. Qian et al., "Rapid determination of amino acids in fruits of ziziphus jujuba by hydrophilic interaction ultra-high-performance liquid chromatography coupled with triple-quadrupole mass spectrometry," Journal of Agricultural and Food Chemistry, vol. 61, no. 11, pp. 2709-2719, 2013.

[24] S.-J. An, T.-C. Kang, S.-K. Park et al., "Oxidative DNA damage and alteration of glutamate transporter expressions in the hippocampal CA1 area immediately after ischemic insult," Molecules and Cells, vol. 13, no. 3, pp. 476-480, 2002.

[25] P. Bezzi, G. Carmignoto, L. Pasti et al., "Prostaglandins stimulate calcium-dependent glutamate release in astrocytes," Nature, vol. 391, no. 6664, pp. 281-285, 1998.

[26] A. Parent and R. Quirion, "Differential localization and $\mathrm{pH}$ dependency of phosphoinositide 1,4,5-IP $3,1,3,4,5-\mathrm{IP}_{4}$ and $\mathrm{IP}_{6}$ receptors in rat and human brains," European Journal of Neuroscience, vol. 6, no. 1, pp. 67-74, 1994.

[27] W. Paschen, C. Gissel, T. Linden, S. Althausen, and J. Doutheil, "Activation of gadd153 expression through transient cerebral ischemia: evidence that ischemia causes endoplasmic reticulum dysfunction," Molecular Brain Research, vol. 60, no. 1, pp. 115122, 1998.

[28] I. K. Hwang, S.-G. Do, K.-Y. Yoo et al., "Chronological alterations of neurofilament 150 immunoreactivity in the gerbil hippocampus and dentate gyrus after transient forebrain ischemia," Brain Research, vol. 1016, no. 1, pp. 119-128, 2004.

[29] D. J. DeGracia, R. Kumar, C. R. Owen, G. S. Krause, and B. C. White, "Molecular pathways of protein synthesis inhibition during brain reperfusion: implications for neuronal survival or death," Journal of Cerebral Blood Flow and Metabolism, vol. 22, no. 2, pp. 127-141, 2002.

[30] H. K. Kimelberg, N. B. Nestor, and P. J. Feustel, "Inhibition of release of taurine and excitatory amino acids in ischemia and neuroprotection," Neurochemical Research, vol. 29, no. 1, pp. 267-274, 2004.

[31] T. Mainprize, A. Shuaib, S. Ijaz, R. Kanthan, H. Miyashita, and J. Kalra, "GABA concentrations in the striatum following repetitive cerebral ischemia," Neurochemical Research, vol. 20, no. 8, pp. 957-961, 1995.

[32] L. Bogaert, D. Scheller, J. Moonen et al., "Neurochemical changes and laser Doppler flowmetry in the endothelin-1 rat 
model for focal cerebral ischemia," Brain Research, vol. 887, no. 2, pp. 266-275, 2000.

[33] N.-G. Li, M.-Z. Shen, Z.-J. Wang et al., "Design, synthesis and biological evaluation of glucose-containing scutellarein derivatives as neuroprotective agents based on metabolic mechanism of scutellarin in vivo," Bioorganic \& Medicinal Chemistry Letters, vol. 23, no. 1, pp. 102-106, 2013.

[34] N.-G. Li, S.-L. Song, M.-Z. Shen et al., "Mannich bases of scutellarein as thrombin-inhibitors: design, synthesis, biological activity and solubility," Bioorganic and Medicinal Chemistry, vol. 20, no. 24, pp. 6919-6923, 2012.

[35] S.-L. Song, N.-G. Li, Y.-P. Tang et al., "Design, synthesis and biological evaluation of scutellarein derivatives as potential antiAlzheimer's disease candidates based on metabolic mechanism," Letters in Drug Design \& Discovery, vol. 9, no. 1, pp. 78-83, 2012.

[36] I. Kara, A. Nurten, M. Aydin et al., "Ischemia/reperfusion in rat: antioxidative effects of enoant on EEG, oxidative stress and inflammation," Brain Injury, vol. 25, no. 1, pp. 113-126, 2011.

[37] G. L. Zhang, Z. W. Zhao, L. Gao et al., "Gypenoside attenuates white matter lesions induced by chronic cerebral hypoperfusion in rats," Pharmacology Biochemistry and Behavior, vol. 99, no. 1, pp. 42-51, 2011. 

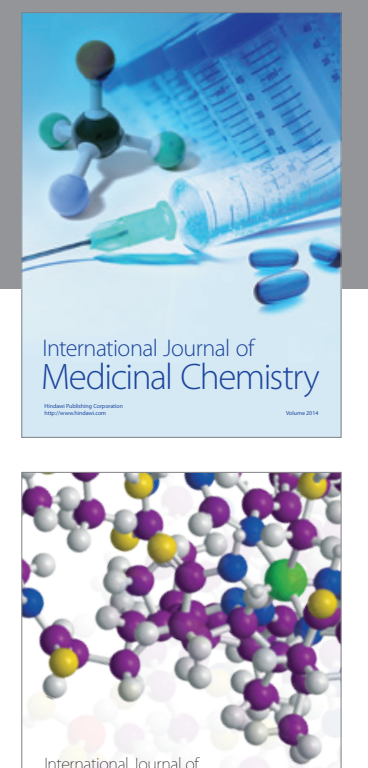

\section{Carbohydrate} Chemistry

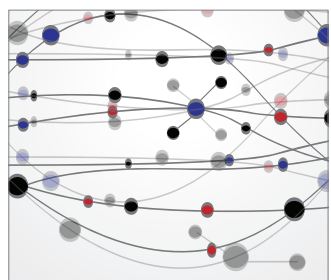

The Scientific World Journal
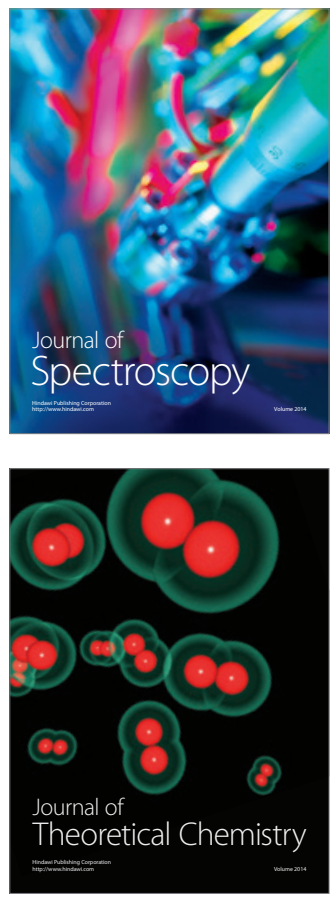
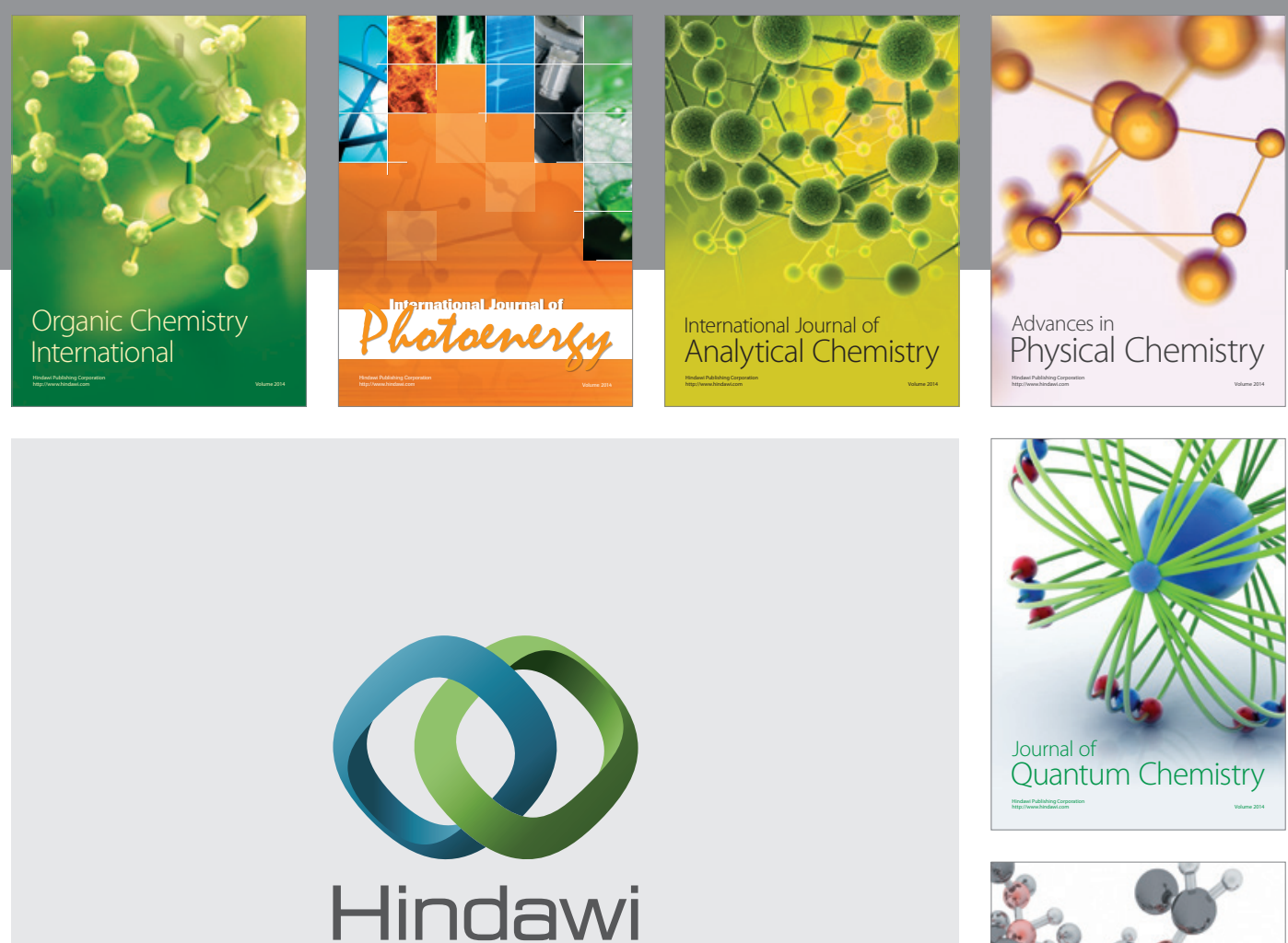

Submit your manuscripts at

http://www.hindawi.com

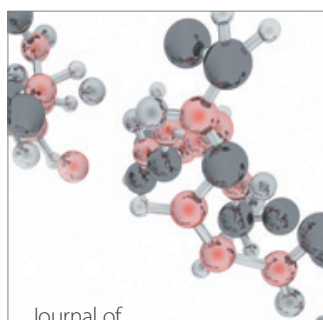

Analytical Methods

in Chemistry

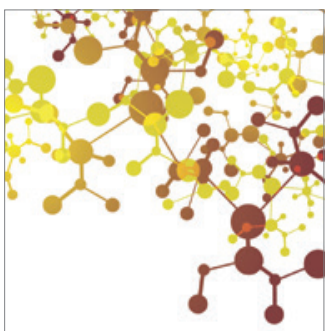

Journal of

Applied Chemistry

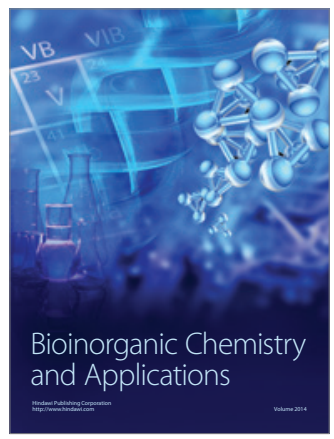

Inorganic Chemistry
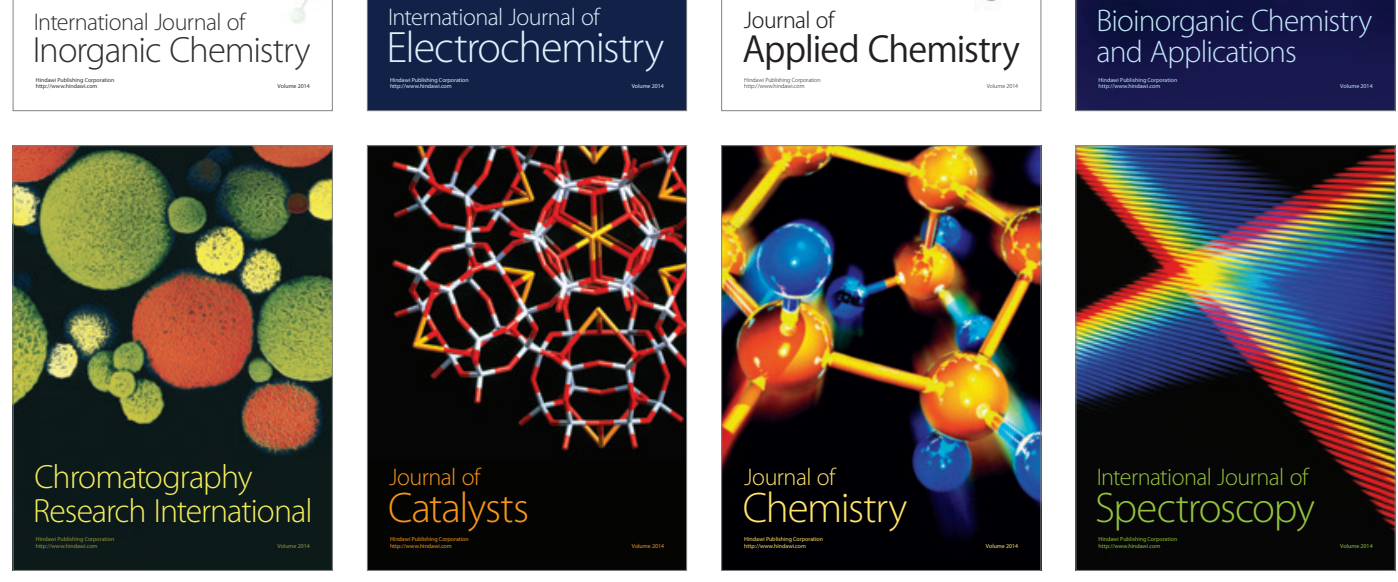